\title{
Nota da Editora
}

\section{Primeiro tempo: população, espaço e ambiente}

Durante o XIX Encontro de Estudos Populacionais da Abep em 2014, surgiu a ideia de se organizar um número temático sobre População, Espaço e Ambiente, como uma atividade dos 25 anos do grupo de trabalho (GT) de mesmo nome. Como o ano de 2015 iniciar-se-ia com as discussões sobre agenda de desenvolvimento sustentável e terminaria com as negociações para os acordos na Conferência das Partes (COP 21), sobre a mudança climática e seus efeitos, o Comitê Editorial da revista entendeu que este seria um momento oportuno para a Abep divulgar trabalhos realizados por seus pesquisadores e contribuir para as discussões em torno destes temas cruciais.

Com muita satisfação se iniciou o trabalho com uma convocatória realizada em conjunto com a coordenação do GT. Os “tempos” do processo de submissão, avaliação, aprovação e publicação foram sempre muito urgentes, mas não mais urgentes do que as complexas ações que precisam ser implementadas para a construção de um mundo socialmente mais justo, economicamente inclusivo e ambientalmente sustentável, respeitando os direitos de todos os seres vivos do planeta e os direitos da natureza. Sem a disposição de todos que participaram deste processo, aos quais se agradece enormemente, não seria possível finalizar a tarefa. 0 trabalho envolveu muitas pessoas e, sem nomear todas, é importante mencionar o coeditor do número, Douglas Sathler, os autores dos 23 trabalhos submetidos, os mais de 45 pareceristas envolvidos, que de maneira recorde e muito competente doaram seus preciosos tempos, os responsáveis pelo processo editorial, os revisores de idioma, muito competentes como sempre, e, principalmente, o apoio inestimável e de grande expertise de George Martine, que, além dos aportes temáticos, colaborou com a tradução e revisão dos textos em inglês.

A enorme urgência de analisar a fundo os processos que envolvem população, meio ambiente e desenvolvimento foi ressaltada de forma dramática com o grande desastre ambiental que ocorreu no Vale do Rio Doce no momento de fechar esse número da revista. Esta calamidade demonstra que o trabalho dos pesquisadores está apenas começando, pois evidencia a necessidade fundamental de incorporar sistematicamente as preocupações ambientais e demográficas na correção de rumo da corrida desenfreada ao crescimento econômico. Tal preocupação esteve presente desde o início do GT e se revela novamente nos artigos ora apresentados. 
A catástrofe de Mariana, Minas Gerais, anunciada até em poesia, exceto aos moradores de Bento Gonçalves e de outros distritos no caminho da lama, ocorreu de maneira violenta no dia 5 de novembro, com o rompimento da Barragem de Fundão. 0 mar de lama se moveu incessante e continuamente, causando desastres diários nas calhas dos Rios Gualaxo do Norte, do Carmo até alcançar o Rio Doce, provocando suas mortes antecipadas, ao longo de seus leitos por mais de 850 quilômetros, quando alcançou o delta do Rio Doce e seguiu em direção ao mar. A perda imediata de 23 vidas humanas é imperdoável, mas talvez muitas outras virão pelos efeitos diretos e indiretos do desastre; a perda de vida dos animais terrestres e da fauna de água doce é incontável e a destruição da vegetação é de difícil recuperação.

Quase 20 dias depois do desastre os responsáveis ainda anunciam que as causas são desconhecidas e estão sendo investigadas. Como em todo registro de óbito, é necessário conhecer as causas básicas e as imediatas. Estas últimas, não restam dúvidas, precisam ainda ser investigadas, mas a causa básica dessas mortes é a ganância dos empresários e interesses econômicos de todos que se beneficiam do modelo extrativista e primário exportador, exacerbado na mineração. A mineradora responsável pela barragem rompida é a Samarco Mineração, uma joint venture da mineradora anglo-australiana BHP Billiton com a Companhia Vale, que retirou Rio Doce de seu nome e agora retirou o Rio Doce do mapa. A forma de exploração desta e de outras mineradoras é a causa básica de morte que tem criado verdadeiras feridas no solo mineiro, como um sarcoma fulminante. Porém, não se pode esquecer de outra causa das mortes, talvez causa intermediária, que é a inépcia de todos, mas principalmente dos gestores do sistema e do governo, que, além de não criarem processos eficientes para a prevenção de desastres, não têm protocolos eficientes estabelecidos para a minimização de danos na ocorrência do evento.

Importante destacar que os efeitos do desastre foram acentuados devido a outros problemas ambientais que a região vem passando ao longo dos anos. 0 extrativismo possibilitou o crescimento de outras atividades econômicas e a expansão das cidades. Mas o aumento dessas atividades, juntamente com a pecuária, destruiu a Mata Atlântica e eliminou a cobertura vegetal da maior parte da Região Sudeste. Sem árvores a chuva que cai no vale do Rio Doce arrasta o solo para o leito dos rios, provocando erosão e impedindo a recarga dos aquíferos, já que não há infiltração suficiente das águas. Assim, os rios vão ficando deteriorados e os aquíferos vazios. Uma população de mais de 3 milhões de pessoas vive no vale do Rio Doce e sofrerá as consequências deste desastre por muito tempo. Ainda, para piorar este cenário, nada tem sido feito para recuperar o meio ambiente e despoluir os rios com tratamento de esgotos e manejo adequado dos resíduos sólidos. Neste momento, chegou-se a um ponto crucial, em que são necessários bons projetos de recuperação do ambiente deteriorado ao longo de vários anos e agravado exponencialmente pelo rompimento da barragem de rejeitos da mineração, bem como o estabelecimento de protocolos adequados que previnam outros desastres que podem ser ainda mais graves. Mas a recuperação do país será ainda mais complicada e demorada, pois a promoção da 
ganância sem regras em nome do “desenvolvimento" é uma catástrofe muito mais ampla que o desastre provocado pela Samarco.

\section{Segundo tempo: contribuições desta edição}

Os mapas, assim como as fotos, em geral causam boas impressões quando bem produzidos; aliás, se costuma dizer que uma imagem vale mais do que mil palavras. Logo, esta edição, por ter o espaço como foco importante e apresentar muitos mapas, está bastante agradável de se ver. Contudo, é comum dizer também que sem as palavras não se pode dizer que uma imagem "vale" mais do que mil palavras. Assim, as análises realizadas pelos autores são mais importantes do que a própria aparência visual da edição, que traz seis artigos, uma nota de pesquisa, três pontos de vista, uma resenha e uma divulgação de livro.

É fazendo uso de palavras contundentes e bem colocadas, em uma análise integral e bem fundamentada, que George Martine e José Eustáquio Diniz Alves levam o leitor a ver as diferentes facetas do tão falado desenvolvimento sustentável. Apesar de serem bastante pessimistas com relação ao futuro do planeta, os argumentos, se contextualizados na calamidade mencionada no primeiro tempo deste editorial, tornam-se ainda mais realistas e podem acordar alguns otimistas, ou pelo menos colocam em dúvida a possibilidade de se alcançar o desenvolvimento sustentável, no quadro em que se dá o crescimento econômico atual. Afinal, como dizem os autores, o termo desenvolvimento sustentável combina duas palavras de sentido cada vez mais opostos e que tendem a se excluir mutuamente. Para fundamentar seus argumentos, os autores fazem uma revisão dos grandes embates teóricos sobre população, desenvolvimento e meio ambiente e realizam uma revisão dos estudos empíricos que mostram: a fraqueza ambiental dos alicerces do progresso; os paradoxos do desenvolvimento tecnológico; e a insustentabilidade do desenvolvimento desigual.

Um grande número de autores, encabeçados por Alisson Barbieri, se coloca um enorme desafio para quantificar, em uma janela de 30 anos, como o aumento da temperatura poderá afetar as populações em diferentes contextos, visto que o aquecimento do planeta é uma das questões mais importantes no arcabouço da mudança climática. Para a análise, os autores partem de alguns pressupostos básicos, dentro das possibilidades dos dados, e utilizam um conjunto significativo de informações para Minas Gerais, que apresenta grande diversidade de ecossistemas. Segundo a hipótese de trabalho, a forma mais adequada para mensurar os efeitos da mudança de temperatura é uma abordagem multidimensional e, para isso, os autores lançam mão de um indicador multidimensional para estimar a vulnerabilidade populacional. Os resultados indicam que os aspectos econômicos e de saúde serão mais afetados por alterações na temperatura, sendo que as populações mais vulneráveis são aquelas que vivem nas regiões mais pobres. Com este trabalho, os autores lançam as bases necessárias para a ampliação de estudos que podem antecipar as consequências que virão com a mudança climática, bem como para que os governantes e as populações possam se preparar para minimizar os danos. 
Também fazendo uso de modelos de projeção, Cristina Guimarães Rodrigues e colegas apresentam uma estimativa do número de internações e mortes devido às enfermidades que podem ser atribuídas à poluição atmosférica e, talvez mais importante, fazem estimativas dos custos para a área de saúde pública em função dessas causas. Diante da escassez de dados nesta área, para enfrentar este enorme desafio, os autores escolhem o Estado de São Paulo, o mais industrializado no país, com suas grandes cidades e altos níveis de poluição, e chegam à conclusão de que, se os níveis de poluição atmosférica forem aqueles observados em 2011, o Estado (ou o país) gastará mais de 1,6 bilhão de reais até 2030 com internações e mortes associadas à poluição, isso sem considerar custos indiretos advindos destas enfermidades e mortes. Um recurso financeiro que poderia ser utilizado para buscar formas de controle da poluição ou mesmo para a implementação de mecanismos de fiscalização e punição, que são essenciais para melhorar a qualidade do ar, como advertem os autores. Os resultados desta pesquisa também abrem caminhos importantes e oferecem argumentos essenciais para o combate às formas de degradação ambiental trazidos pelo avanço tecnológico, fazendo a conexão direta sobre os efeitos econômicos perversos que este pode gerar.

Pensar no futuro das grandes cidades é igualmente uma preocupação de Glauco Umbelino e Clodoveu Davis Jr., que apresentam um artigo com uma simulação do número de domicílios que a lei atual de uso e ocupação do solo urbano de Belo Horizonte permitiria, caso fosse implementada em seu máximo. Os autores utilizam uma metodologia que fornece resultados para diferentes cenários de previsão, os quais são essenciais como ferramentas para gestores municipais, que têm potencial importante para auxiliar no planejamento da expansão da mancha urbana. Os resultados mostram, por exemplo, que a cidade de Belo Horizonte poderia vir a ter até 1.405.413 domicílios, partindo da base de 798.940 em 2011 , caso a lei fosse praticada em seu máximo permitido. De maneira complementar, os autores argumentam que o método pode ser utilizado nas projeções domiciliares e populacionais de pequenas áreas, principalmente, em escalas mais desagregadas no interior das grandes cidades.

As imagens do desastre de Mariana, citado anteriormente, continuam muito presentes, pois as consequências ainda estão sendo vivenciadas. No entanto, as imagens logo se vão e os novos desastres nos fazem esquecer de outras tragédias ambientais. Como estes não devem ser esquecidos, a autora Luciana de Resende Londe e colegas, do Centro Nacional de Monitoramento e Alertas de Desastres Naturais (Cemaden) criado em 2011, fazem o leitor repensar nas inundações que ocorreram em 2008 em Santa Catarina e em 2010 em Pernambuco (que também atingiram Alagoas). Os desastres ocorreram após fortes chuvas, causando inundações e enormes deslizamentos. 0 objetivo do artigo é conhecer as características da área de saúde, antes e depois do desastre, nos municípios afetados que declararam estado de calamidade pública, e analisar os impactos causados por estes. Os resultados indicam diferenças sociais muito diversas nos dois Estados, como esperado, mas os impactos foram severos nos dois locais, como, por exemplo, o aumento dos casos 
de leptospirose após os desastres. Chama atenção que a maior gravidade ocorreu em Santa Catarina, que possui indicadores econômicos melhores e tem rede de assistência médica mais diversificada, mas isso tem a ver com as questões ambientais e geográficas.

O último artigo, de autoria de Álvaro de Oliveira D’Antona, Ricardo de Sampaio Dagnino e Maria do Carmo Dias Bueno, apresenta uma análise da presença de populações em áreas protegidas do Estado do Pará, utilizando dados do Censo Demográfico de 2010, que permitiram um estudo geográfico bastante detalhado devido à identificação das coordenadas geográficas dos domicílios, a partir da coleta de dados do censo por meio dos PDAs. Os autores utilizam os dados dessas coordenadas para colocar os domicílios em grades estatísticas de resolução espacial média de $1,15 \mathrm{~km}$ e conseguem identificar $81,7 \%$ deles com este método. Os demais foram localizados nas grades a partir da desagregação pelo método dasimétrico, comumente utilizado por outros autores. Posteriormente, os dados demográficos foram associados a esta escala com informações sobre uso e cobertura do solo em áreas protegidas. Os autores encontram usos urbanos associados a outros usos e coberturas da terra nessas áreas protegidas, chamando a atenção para a necessidade de abordagens mais integradas nos estudos sobre urbanização e mudanças no uso e cobertura da terra.

A nota de pesquisa apresentada por Douglas Sathler, Susana B. Adamo e Everton E. C. Lima relata a parceria entre algumas universidades brasileiras e um centro norte-americano da Universidade de Columbia para investigar os efeitos das mudanças climáticas e possíveis ações de mitigação no setor florestal, focando no caso da Amazônia. A nota, além de uma discussão conceitual, coloca em destaque as possíveis contribuições que a pesquisa na área de demografia pode oferecer com relação ao desmatamento e desenvolvimento sustentável local na Amazônia Legal. Os autores chamam a atenção para a importância da participação de redes locais na busca de soluções mitigadoras dos efeitos das mudanças climáticas nos municípios da Amazônia, se não em contraposição, pelo menos em colaboração com as ações das redes internacionais.

Os três últimos textos apresentados nesta edição brindam importantes pontos de vista sobre os eventos que marcaram o ano de 2015 na área ambiental e na agenda global de desenvolvimento pós-2015. José Eustáquio Diniz Alves analisa os três grandes eventos que marcaram o septuagésimo aniversário da criação da Organização das Nações Unidas (ONU): a Terceira Conferência Internacional sobre Financiamento para o Desenvolvimento (FpD3); a Cúpula do Desenvolvimento Sustentável da ONU, que aprovou os Objetivos de Desenvolvimento Sustentável (ODS); e a COP 21, tendo como principal finalidade costurar um novo acordo internacional para limitar o aumento da temperatura global até 2100.0 autor afirma que, embora articulados e bem intencionados, os três eventos não têm se mostrado capazes de dar um novo rumo ao modelo hegemônico de desenvolvimento, que carece, por um lado, de sustentação ecológica e, de outro, de justiça distributiva em sua arquitetura social. No segundo ponto de vista, Landy Sánchez Peña faz uma análise importante sobre como os Objetivos de Desenvolvimento Sustentável incorporam as questões de 
meio ambiente, mas pouco incluem os temas da dinâmica demográfica e, por outro lado, como a agenda Regional de População de Desenvolvimento, conhecida como Consenso de Montevidéu, de fato pouco dialoga com os temas ambientais. 0 ponto de vista de Susana B. Adamo traz importantes questões sobre adaptação e mitigação, que, segundo a autora, são aspectos insuficientemente considerados nas discussões da Conferência sobre o Clima (COP 21). Adamo afirma que a incapacidade de lidar com a mitigação e adaptação dentro de uma abordagem equilibrada e com a devida consideração da dinâmica populacional na estrutura global, de fato, tem obstruído análises e esforços em direção à resolução destes problemas em nível técnico.

A resenha de George Martine apresenta uma crítica contundente a vários aspectos do recente livro de Jeffrey Sachs, The age of sustainable development. 0 autor reconhece o esforço importante e análises bem realizadas nos capítulos do livro, mas afirma que os pressupostos teórico-ideológicos utilizados por Sachs são falhos, o que os torna, como ele diz, uma mensagem perigosamente enganosa. Para Martine, o diagnóstico feito por Sachs está totalmente correto e realizado com precisão, mas a prescrição para a solução dos problemas somente agravará estes, por propor mais do mesmo.

Finalmente, apresenta-se nesta edição uma divulgação de livro, oferecida por Ricardo Ojima, que faz uma justa homenagem ao trabalho realizado por Daniel Hogan, não somente em função de suas contribuições teórico-metodológicas, mas também pela criação de toda uma geração de pesquisadores, que ajudaram a dar sustentabilidade à área de população e ambiente na Abep.

Importante encerrar dizendo que, no processo de avaliação e revisão, às vezes muito mais demorado do que os prazos de publicação, alguns artigos ainda estão em fase de reformulação e, quando completado este processo, ainda poderão ser publicados nos próximos números da revista. De toda maneira, devido à importância do tema, espera-se que muitos outros trabalhos deem continuidade às discussões colocadas neste número temático.

Por último, a Diretoria da Abep e a editora da Rebep fazem um agradecimento explícito à Fundação Carlos Chagas pelo apoio financeiro à revista, o que possibilitou publicar, neste ano, as edições quadrimestrais.

Boa leitura! 